\title{
THE INFLUENCE OF JOB ANALYSIS ON ORGANIZATIONAL PERFORMANCE: EMPIRICAL EVIDENCE FROM MANUFACTURER COMPANY IN INDONESIA USING PLS-SEM
}

\author{
Mulyana Dede Hendri*, Muhyi Herwan Abdul, Rizal Muhamad \\ Department of Business Administration, University of Padjadjaran, Bandung, Indonesia \\ *E-mail: achmad16012@mail.unpad.ac.id
}

\begin{abstract}
This study examines the influence of Job Analysis of a manufacturing company. In this study, two factors allegedly affect a Job Analysis of manufacturing companies. These factors were derived from several aspects, namely Job Description, and Job Specification. Then, these factors influence organizational performance with six dimensions, namely Job Quality and Quantity, Timeline, Cost Effectiveness, Supervision, and Impact. In analyzing to measure the relationship is used Structural Equation Modeling Partial Least Squares (SEM PLS). This study uses primary data based on the company's employees. The data was collected from 73 respondents in PT. Indonesia TRC Industry. The results of this study indicate that the Job Analysis has a significantly affected the performance of the manufacturing company. This paper also shows that employee job analysis can be a powerful tool to enhance organizational performance.
\end{abstract}

\section{KEY WORDS}

Job analysis, job description, job specification, performance, manufacture company.

Generally, Job analysis is one of the most important activities of human resource management and can perform multi-functions (Russell \& Bernardin, 1993). A regular or proactive job analysis practices help to identify factors that shape the employees' motivation and job satisfaction ( $\mathrm{Li}$ et al., 2008). The researchers have established co-relationship between organizational performance and job analysis in context to human resource management but the relationship between human resource management practices like job analysis and job performance, the intervening process recruitment, connecting job analysis is yet to be explored in a full flow (Bernardin, 2002).

Companies that regularly conduct job analysis possess a much better knowledge of their strengths and limitations and can take timely corrective action to improve any deficiencies in their skills and job behavior (Clifford, 1994). Brannick \& Levine (2002) defined the job analysis as an organized process whereby nature of a job is discovered. Job or task is divided into smaller units. Bernardin, (2002) that the collection and processing of job related information and other related tasks and qualifications through job analysis was a base for human resource management (HRM). Job analysis has a vital role. Sanchez \& Levine (2000) that erroneous practice of the job analysis may affect other HR activities based on it. Former research by Brannick \& Levine (2002), Cronshow (2012), Dierdorff \& Wilson (2003), Pujangkoro (2004), Schneider \& Konz (1989), Siddique (2004), and Singh (2008) on job analysis persistent on the variable like demographic in job analysis ratings. $\mathrm{Li}$ et al. (2008) stressed the significance of job analysis as a strategic HRM practice linked with the organizational performance. Suthar et al. (2014) recommended that with the recognition of the Human Resource-Performance linkage, organizations vigorously adopting job analysis as a human resource strategy were likely to grow more and put on aggressive benefits.

Carmeli et al. (2013), Siddique (2004), Singh et al. (2007) exposed diverse results on the linkage between inspiring job characteristics and job performance and outcome like turnover and absenteeism. Burcharth et al. (2017) and Carmeli et al. (2013) found inconsistent results and suggested that background might play a vital role in moderating employee reactions. Russell \& Bernardin (1993) supported the hypothesized linkage between stimulating job characteristics and job satisfaction, the extent of the relationship 
between the core job characteristics and outcomes appeared to be moderate rather than high.

Statt (2004) discussed that the job description outlines the job tasks, duties and responsibilities and serves as a guide for the recruitment and selection process going forward in general, a job description be relating to all the technical, administrative and managerial aspects of the job, the job title, job summary, job duties, tasks and outputs. Bernardin (2002) further described job description as a written narrative of the tasks to be performed and what it entails.

As defined by Werther \& Davis (1993) "Job evaluation is a systematic process used to determine the worth of jobs and creating a link between job worth and salary". Meier \& O'Toole (2002) further clarified that as the worth of a job is determined, it might be seen in terms of salary and other fringe benefits in accordance with the existing salary structure of the organization. Goffin et al. (2011) intimated a widely used method of job evaluation called point-based job evaluation method. Further studies of Chang et al. (2017), Goffin et al. (2011), Kim et al. (2004) and Pfeffer (2009) have also tested the validity and outcome of the job evaluation system in vogue used for salary determination.

Job specification is a written statement of qualifications, traits, physical and mental characteristics that an individual must possess to perform the job duties and discharge responsibilities effectively. In this, job specification usually developed with the co-operation of personnel department and various supervisors in the whole organization A study by Russell \& Bernardin (1993) assesses the accuracy and usefulness of job descriptions by examining the best way to form, design, and make job descriptions David \& Carolina (2011) defined that job specification deals with the personal aspects of the job and education or qualification background, skills, knowledge and ability. In a layman human resources term, the job description can be associated with the hard issues whilst the job specification may focus some soft issues.

\section{METHODS OF RESEARCH}

This research uses quantitative methods that can explain the causal relationships between the variables studied. Source of primary data comes from the questionnaire given to the respondents, while the secondary data comes from the result of previous studies and the related theories. The analysis model uses SEM through Partial Least Squares approach with SmartPLS-3 software. Population in this paper are all employee in PT. Indonesia TRC Industry, with the 73 Top Lovel Management or Managers as respondents. All respondents were chosen by using probability sampling using the purposive sampling method.

Malhotra (1981) stated that the likert scale submitted to respondents should use a 5point scale, namely 5 = strongly agree, $4=$ agree, $3=$ neither agree nor disagree, $2=$ disagree, 1 = strongly disagree. The construction of the questionnaire came from four variables, based on theoretical studies reduced to dimensions and indicators of research with 45 items of research questionnaire.

The data analysis used to see the influence and hypothesis testing by using the Structural Equation Model (SEM). The data processing in this research uses Partial Least Square (PLS) with SmartPLS-3 software because all the variables are latent variables and they are measured by dimensions and indicators. In the current study, we have adopted the multidimensional constructs include combinations of composite and reflective measurement (Jarvis et al., 2003). This means that both for the first-order constructs and the second-order construct the type of measurement model can and should be determined separately (MacKenzie et al., 2005). A particularly important configuration of second-order constructs is a composite of common factors. In a composite of common factors configuration, the firstorder constructs employ a reflective measurement model, whereas the second-order construct is a composite formed by the first-order constructs. This is the most frequently used approach in research in the social sciences (Ringle et al., 2012), implying a need to deeper examine this type of hierarchical component model. 
In this paper, latent variable Job Analysis is a second-order reflective constructs as formed by first-order reflective such are Job Description with ten indicators, and Job Specification with three indicators (Fabi \& Pettersen, 1992; Schneider \& Konz, 1989; Singh, 2008). Organizational Performance is a second-order reflective constructs as formed by firstorder reflective such as Job Quality with five indicators, Job Quantity with four indicators, Timeline with five indicators, Cost Effectivity with five indicators, Supervision with three indicators, and Impact with five indicators (Bernardin, 2002; Russell \& Bernardin, 1993).

\section{RESULTS AND DISCUSSION}

This research uses the Structural Equation Model (SEM) analysis technique with Partial Least Square (PLS). We followed the Chin (1998) and Ghozali (2014) study to run the second order confirmatory factor analysis approach. In the first step, we have evaluation outer model with validated the reflective type first-order constructs and reported the Cronbach's alpha, composite reliability, and average variance extracted (AVE). In the second step is an analysis of the second-order constructs, we took the latent variable score from the first model and made a repeated indicators approach (Chin, 1998; Ghozali, 2014). For the reflective measurement model confirmation to run the bootstrapping on 500 resampling, we have reported the weights and the maximum variance inflation factor or path coefficients to validate the measurement model for reflective constructs (Hair et al., 2016).

According to Chin (1998) and Gaskin et al. (2018) for construct reliability testing was measured by Cronbach's alpha and composite reliability. Constructs are stated reliable if they have Cronbach's alpha above 0.60 and composite reliability values above 0.70 . While the sufficient value of average variance extracted (AVE) to measure the validity is 0.5 (Ghozali, 2014). Based on the criteria of Table 1, then the output of the data shows the results of all criteria of the outer model can be fulfilled so that it can be concluded that the research data has good validity and reliability, therefore it can proceed to the analysis of the inner model.

Table 1 - Cronbach alpha, composite reliability and average variance extracted

\begin{tabular}{|c|c|c|c|c|}
\hline $\begin{array}{c}\text { Second-order } \\
\text { constructs }\end{array}$ & First-order constructs & $\begin{array}{c}\text { Cronbach's } \\
\text { Alpha }\end{array}$ & $\begin{array}{c}\text { Composite } \\
\text { Reliability }\end{array}$ & $\begin{array}{c}\text { Average Variance } \\
\text { Extracted }\end{array}$ \\
\hline \multirow{2}{*}{ Job Analysis } & Job Description & 0.883 & 0.905 & 0.490 \\
\cline { 2 - 5 } & Job Specification & 0.780 & 0.872 & 0.696 \\
\hline \multirow{5}{*}{ Performance } & Job Quality & 0.874 & 0.909 & 0.667 \\
\cline { 2 - 5 } & Job Quantity & 0.947 & 0.962 & 0.864 \\
\cline { 2 - 5 } & Timeline & 0.906 & 0.930 & 0.728 \\
\cline { 2 - 5 } & Cost effectiveness & 0.945 & 0.958 & 0.821 \\
\cline { 2 - 5 } & Supervision & 0.726 & 0.843 & 0.642 \\
\cline { 2 - 4 } & Impact & 0.903 & 0.928 & 0.721 \\
\hline
\end{tabular}

The results of inner model testing are done in two steps, first by evaluating the model between constructs first-order and the second-order construct (Gaskin et al., 2018). The aim is to see how much the reflective level and the significant influence of the first order construct reflect the second-order construct. Second, evaluating the model between second-order constructs or structural models. The structural model was evaluated by using $R$ square for endogenous constructs and comparing t-statistics with t-tables at a confidence level of $95 \%$ or with the value of loading factor 1.96 .

Based on the results of running SmartPLS-3, all loading factors on indicators and dimensions that are first-order constructs have values above 0.50 , thus indicating that the indicators and dimensions used in this research are reliable. This shows that the indicators and dimensions used in this paper reflect latent variables. The highest first-order construct is a Job Description with a score of 0.962 . This finding proves that Job Description can create a good performance of the manufacturing companies. Picture 1 is the result of the value of loading factors in the first-order construct. 


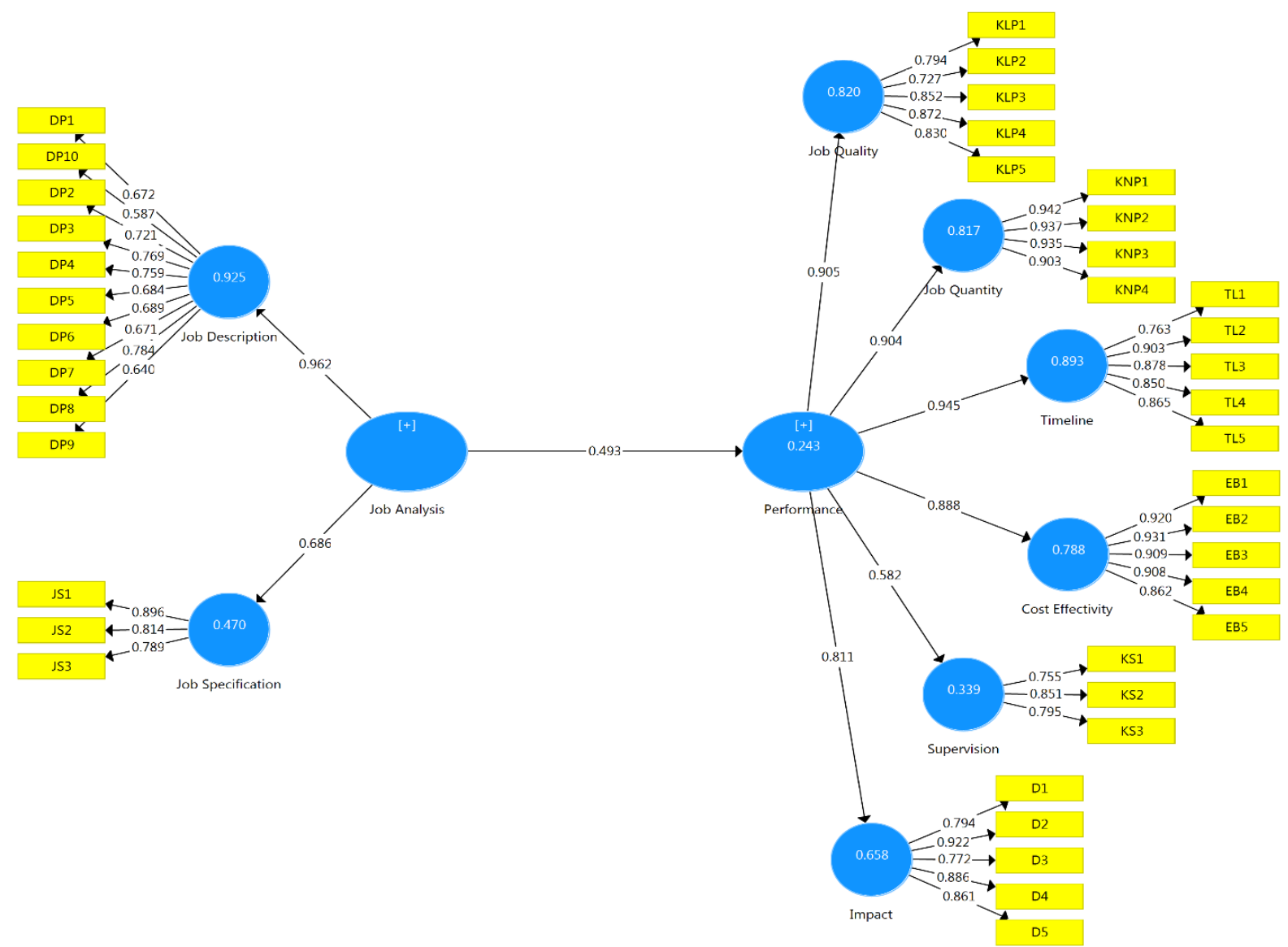

Figure 1 - Loadings factor results of the SEM-PLS Algorithm

Inner model analysis between second-order constructs is carried out to ensure that the structural model built is robust and accurate (Ghozali, 2014). Robust regression is a regression method that is used when the error distribution data is abnormal or there are some outliers that influence the model (Chin, 1998). Evaluation of the inner-order construct inner model can be seen from several indications which include the coefficient determination $\left(R^{2}\right)$, Predictive Relevance $\left(Q^{2}\right)$, Goodness of Fit Index (GoF).

The following is the value of $R^{2}$ output software smartPLS-3.

Table 2 - Value $R^{2}$ of output software

\begin{tabular}{|c|c|c|}
\hline $\mathrm{n} / \mathrm{n}$ & $R$ Square & $R$ Square Adjusted \\
\hline Job Analysis $\rightarrow$ Performance & 0.243 & 0.233 \\
\hline
\end{tabular}

According to Chin (1998), the $R$ square value is 0.67 (strong), 0.33 (moderate) and below 0.19 (weak). This research model is categorized to have a strong relationship between the variables being analyzed. In this research, there are two endogenous variables namely entrepreneurial orientation and sustainable competitive advantage and two exogenous variables. Based on $R$ square and $R$ square adjusted values, there is a moderate relationship between exogenous variables either independently or together.

To calculate $Q^{2}$ the following formula can be used:

$$
Q^{2}=1-\left(1-R 1^{2}\right)\left(1-R 2^{2}\right) \ldots\left(1-R n^{2}\right)=0.059049
$$

This test is conducted to determine the predictive capability with the blindfolding procedure. According to Chin (1998), if the value obtained is 0.02 then the model has a small predictive capability. If the value obtained is 0.15 then the model has a moderate predictive 
capability. And if the value obtained is 0.35 then the model has a large predictive capability. If the calculation of the $Q^{2}$ value is 0.059 , then the model has a small predictive capability. $R^{2}$.

Goodness of Fit index (GoF) is obtained by the AVE value squared and multiplied by

$$
A V E=\frac{\sum \lambda_{i}^{2}}{\lambda_{i}^{2}+\sum_{i} \operatorname{var}\left(\mathcal{E}_{i}\right)}=0.913
$$

Where: $\lambda_{i}$ is a loading component to the indicator and $\operatorname{var}\left(\varepsilon_{i}\right)=1-\lambda_{i}^{2}$.

GoF values in SEM-PLS are calculated manually (Tenenhaus et al., 2005) with the following formula:

$$
\mathrm{GoF}=\sqrt{A V E^{2} x R^{2}}
$$

With AVE of 0.913 and the average $R$ Square in first-order is 0.5541 . So that the GoF can be calculated as follows:

$$
\mathrm{GoF}=\sqrt{0.913^{2} \times 0.913}=0.872
$$

According to Tenenhaus et al. (2005) GoF small value $=0.1$, medium GoF $=0.25$ and large $\mathrm{GoF}=0.38$. Based on the calculation of the GoF value the model has a large GoF value so that the formed a model represents the real phenomenon.

The test of hypotheses in SEM PLS is done with a bootstrapping process that produces $\mathrm{t}$-statistics values. If the $\mathrm{t}$ - statistics value is greater than that of the t-statistic with a $95 \%$ confidence level $(>1.96)$ then the hypothesis is significant. Here are the results of bootstrapping of SmartPLS-3 software. Whereas to find out how much influence among the variables, then find out the value of the loading factor of the original sample output of smartPLS-3. This can be seen in the path coefficients table on the smartPLS-3 output. The following table presents the Path Coefficients.

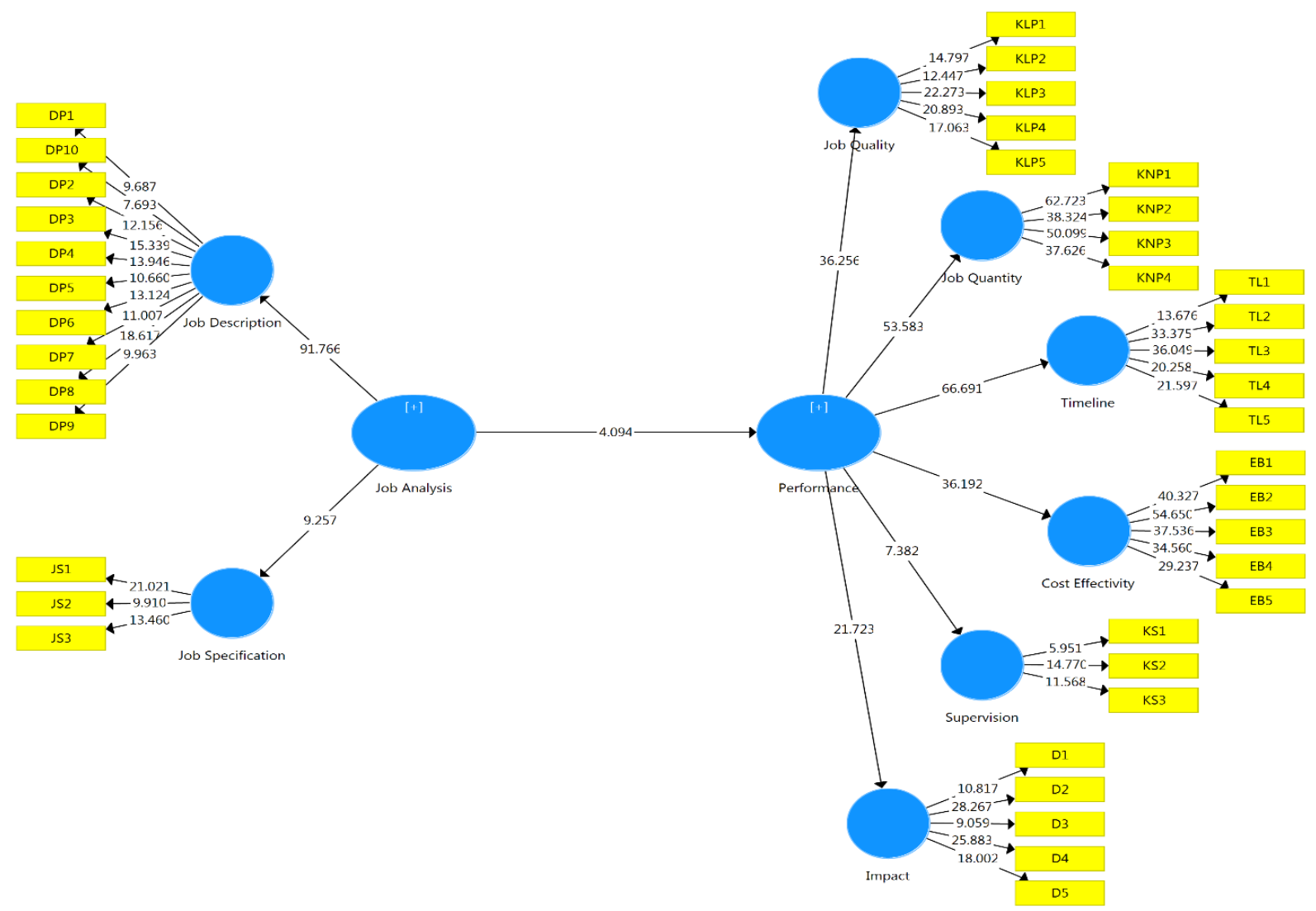

Figure 2 - Structural model of the second-order constructs of SEM-PLS 
Based on output of the bootstrapping from SmartPLS-3 software, the path coefficient values are presented in the fig. 2 . The t- statistics obtained that as many as the hypotheses have a value of $\mathrm{t}$ - statistics above 1.96. This means that from the research hypotheses, that is proved to have a positive and significant influence. Job Analysis has affected the performance on manufacturing company. All first-order constructs also showed significant effect between second-order and first-order constructs.

\section{DISCUSSION OF RESULTS}

The results of this research confirm the findings of previous research that job analysis is positively related to organizational performance (Fabi \& Pettersen, 1992; Gatewood, Feild, \& Barrick, 2008; Neuman \& Wright, 1999; Pfeffer, 2009; Raymark, Schmit, \& Guion, 1997; Saif et al., 2013). Thus, there is a tendency that organizational performance will increase when job analysis created by job description and specification (Russell \& Bernardin, 1993).

In this context, the analysis shows that job descriptions act primarily to achieve a job quantity and quality, and also give a good timeline to produce product (Conte et al., 2005; Saif et al., 2013). SEM-PLS showed a higher number on timeline as a dimension that build second-order construct performance with 0.945 (> 0.5). Russell \& Bernardin (1993) argue that the clear a job description and specification can give the ability to reduce good quality product with innovative in operational, production, and delivery to customers.

This paper explains that job analysis has a significant effect on performance at the manufacture company. Analytical unit on this paper uses 2 top management, 24 middle management and 47 first line management at PT. Indonesia TRC Industry. The SEM-PLS test results show the original sample is positive with loading factor 0.493 and the result of the t-statistic value is 3.933 (> 1.94). These results indicate that most employees as the respondents in PT. Indonesia TRC Industry have a good job analysis. Based on interviews, employee activity had been effective especially on job description.

Finally, job analysis is a source of company performance when job description given a support to employees makes it clear to doing a job on a company (Hussain, Ismail, \& Akhtar, 2015). Job analysis is the source of achieving cost efficient and create company background and employees characteristic to become skilled, competent in their respective fields, quickly adapt to the demands of many jobs, and impact the company by saving production timeline (Clifford, 1994; Cronshow, 2012).

As noted above, in terms of company background and demographic characteristics, only employee training and development showed a modest relationship with performance. It seems that an increasing exposure of companies, regardless of their size, age or ownership status, to innovative human resources practices and other strategic factors in the current global business environment has somewhat mitigated the weight of such background characteristics in shaping company performance.

\section{CONCLUSION}

The empirical results show job analysis directly affects the performance of PT. Indonesia TRC Industry. Job analysis creates job quality, job quantity, effective timeline, cost effectiveness, supervision, and good impact in Manufacture Company. Job analysis reflected two dimensions; these are job description and job specification. The conclusion of the results of this paper ensures that PT. Indonesia TRC Industry have been able to create good performance. Problems faced by company such as human resources and job of employees can be overcome by strengthening job analysis. If the job analysis in the company is strong, then the company will have the opportunity to improve performance.

\section{REFERENCES}

1. Bernardin, H. J. (2002). Human resource management: An experiential approach. Irwin Professional Pub. 
2. Brannick, M. T., \& Levine, E. L. (2002). Job analysis: Methods, research, and applications for human resource management in the new millennium. Sage Publications London.

3. Burcharth, A., Knudsen, M. P., \& Søndergaard, H. A. (2017). The role of employee autonomy for open innovation performance. Business Process Management Journal, 23(6), 1245-1269. https://doi.org/10.1108/BPMJ-10-2016-0209

4. Carmeli, A., Friedman, Y., \& Tishler, A. (2013). Cultivating a resilient top management team: The importance of relational connections and strategic decision comprehensiveness. Safety Science, 148-159. https://doi.org/10.1016/j.ssci.2012.06.002

5. Chang, Y.-Y., Chang, C.-Y., \& Chen, C.-W. (2017). Transformational leadership and corporate entrepreneurship: Cross-level mediation moderation evidence. Leadership \& Organization Development Journal, 38(6), 812-833. https://doi.org/10.1108/LODJ-102015-0219

6. Chin, W. W. (1998). The partial least squares approach to structural equation modeling. In Modern methods for business research. https://doi.org/10.1016/j.aap.2008.12.010

7. Clifford, J. P. (1994). Job analysis: Why do it, and how should it be done? Public Personnel Management, 23(2), 321-340.

8. Conte, J. M., Dean, M. A., Ringenbach, K. L., Moran, S. K., \& Landy, F. J. (2005). The relationship between work attitudes and job analysis ratings: Do rating scale type and task discretion matter? Human Performance. https://doi.org/10.1207/s15327043hup1801_1

9. Cronshow, S. F. (2012). Functional Job Analysis. In The Handbook of Work Analysis: Methods, Systems, Applications and Science of Work Measurement in Organizations. https://doi.org/10.1111/j.1365-2788.2010.01291.x

10. David, F. R., \& Carolina, S. (2011). Strategic Management Concepts and Cases. Zeitschrift für Personalforschung (Vol. 28). https://doi.org/10.1688/ZfP-2014-03-Rowold

11. Dierdorff, E. C., \& Wilson, M. A. (2003). A meta-analysis of job analysis reliability. Journal of Applied Psychology. https://doi.org/10.1037/0021-9010.88.4.635

12. Fabi, B., \& Pettersen, N. (1992). Human resource management practices in project management. International Journal of Project Management. https://doi.org/10.1016/02637863(92)90060-M

13. Gaskin, J., Godfrey, S., \& Vance, A. (2018). Successful System Use: It's Not Just Who You Are, But What You Do. AIS Transactions on Human-Computer Interaction, 10(2), 57-81.

14. Gatewood, R. D., Feild, H. S., \& Barrick, M. R. (2008). Human resource selection. In Human resource selection. https://doi.org/10.15713/ins.mmj.3

15. Ghozali, I. (2014). SEM Metode Alternatif dengan menggunakan Partial Least Squares (PLS). Semarang: Badan Penerbit Universitas Diponegoro.

16. Goffin, R. D., Rothstein, M. G., Rieder, M. J., Poole, A., Krajewski, H. T., Powell, D. M., ... Mestdagh, T. (2011). Choosing job-related personality traits: Developing valid personality-oriented job analysis. Personality and Individual Differences. https://doi.org/10.1016/j.paid.2011.06.001

17. Hair Jr, J. F., Hult, G. T. M., Ringle, C., \& Sarstedt, M. (2016). A primer on partial least squares structural equation modeling (PLS-SEM). Sage Publications.

18. Hussain, J., Ismail, K., \& Akhtar, C. S. (2015). Linking entrepreneurial orientation with organizational performance of small and medium sized enterprises: A conceptual approach. Asian Social Science, 11(7), 1-10. https://doi.org/10.5539/ass.v11n7p1

19. Jarvis, C. B., MacKenzie, S. B., \& Podsakoff, P. M. (2003). A critical review of construct indicators and measurement model misspecification in marketing and consumer research. Journal of Consumer Research, 30(2), 199-218.

20. Kim, S., Lee, J., Yu, K., Kim Jean Lee, S., \& Yu, K. (2004). Corporate culture and organizational performance. Journal of Managerial Psychology, 19(1), 340-359. https://doi.org/10.1108/02683940410537927

21. Li, D., Eden, L., Hitt, M. A., Ireland, R. D., Sebaa, A. A., Wallace, J., ... Raver, J. L. 
(2008). Strategic consensus, top management teams, and innovation performance. Leadership \& Organization Development Journal, 29(4), 340-358. https://doi.org/10.1108/01437721011073373

22. MacKenzie, S. B., Podsakoff, P. M., \& Jarvis, C. B. (2005). The problem of measurement model misspecification in behavioral and organizational research and some recommended solutions. Journal of Applied Psychology, 90(4), 710.

23. Malhotra, N. K. (1981). A scale to measure self-concepts, person concepts, and product concepts. Journal of Marketing Research, 456-464.

24. Meier, K. J., \& O'Toole, L. J. (2002). Public Management and Organizational Performance: The Impact of Managerial Quality. Journal of Policy Analysis and Management, 21(Fall), 689-700.

25. Neuman, G. A., \& Wright, J. (1999). Team effectiveness: Beyond skills and cognitive ability. Journal of Applied Psychology. https://doi.org/10.1037/0021-9010.84.3.376

26. Pfeffer, J. (2009). Low Grades for Performance Reviews. BusinessWeek, (4141), 68. Retrieved from http://ezproxy.library.capella.edu/login?url=http://search.ebscohost.com/login.aspx?direct $=$ true $\& \mathrm{db}=\mathrm{bth} \& \mathrm{AN}=43369246 \&$ site $=$ ehost-live $\&$ scope $=$ site

27. Pujangkoro, S. A. (2004). Analisis Jabatan ( Job Analysis ). Analisis Jabatan ( Job Analysis ).

28. Raymark, P. H., Schmit, M. J., \& Guion, R. M. (1997). Identifying potentially useful personality constructs for employee selection. Personnel Psychology. https://doi.org/10.1111/j.1744-6570.1997.tb00712.x

29. Ringle, C. M., Sarstedt, M., \& Straub, D. (2012). A critical look at the use of PLS-SEM in MIS Quarterly.

30. Russell, J., \& Bernardin, J. (1993). Human Resources Management An Experiential Approach. Singapore: Mc. Graw.

31. Saif, N., Khan, M. S., Rehman, K., Rehman, S. ur, Nawa, T., \& Naqeeb, M. (2013). Competency based job analysis. International Journal of Academic Research in Accounting Finance and Management Sciences. https://doi.org/ISSN: 2225-8329

32. Sanchez, J. I., \& Levine, E. L. (2000). Accuracy or consequential validity: which is the better standard for job analysis data? Journal of Organizational Behavior: The International Journal of Industrial, Occupational and Organizational Psychology and Behavior, 21(7), 809-818.

33. Schneider, B., \& Konz, A. M. (1989). Strategic job analysis. Human Resource Management. https://doi.org/10.1002/hrm.3930280104

34. Siddique, C. M. (2004). Job analysis: A strategic human resource management practice. International Journal of Human Resource Management. https://doi.org/10.1080/0958519032000157438

35. Singh, P. (2008). Job analysis for a changing workplace. Human Resource Management Review. https://doi.org/10.1016/j.hrmr.2008.03.004

36. Singh, P., Parker, J. A., \& Nadim, A. (2007). Employee relations in small businesses: examining underdeveloped issues. International Journal of Human Resources $\begin{array}{llll}\text { Development and } \quad \text { Management, } & 7(3 / 4), & \end{array}$ https://doi.org/10.1504/IJHRDM.2007.017138

37. Statt, D. A. (2004). The Routledge dictionary of business management. Routledge.

38. Suthar, B. K., Chakravarthi, T. L., \& Pradhan, S. (2014). Impacts of Job Analysis on Organizational Performance: An Inquiry on Indian Public Sector Enterprises. Procedia Economics and Finance, 11, 166-181.

39. Tenenhaus, M., Vinzi, V. E., Chatelin, Y.-M., \& Lauro, C. (2005). PLS path modeling. Computational Statistics \& Data Analysis, 48(1), 159-205.

40. Werther, W. B., \& Davis, K. J. (1993). Influence of Organizational Culture and Job Involvement on Organizational Commitment. Journal of Current Computer Science and Technology, 1(1), 33-39. 